\title{
INVESTIGATING OF FOREST CHANGE IN GOLESTAN PROVINCE USING LANDSAT IMAGE
}

\author{
M. Zoraghi ${ }^{1}$, R. Saadi ${ }^{1}$, M. Hasanlou ${ }^{1, *}$ \\ ${ }^{1}$ School of Surveying and Geospatial Engineering, College of Engineering, University of Tehran \\ (ramin.saadi, mohamad.zoraghi, hasanlou)@ut.ac.ir
}

Commission VI, WG VI/4

KEY WORDS: Change detection, Post classification comparison, Golestan province, Land use, Remote sensing

\begin{abstract}
:
In recent years, forests in the north of the country have been attacked due to human interference. Increasing population and development of residential and agricultural areas have led to deforestation. Change detection is one of the most common methods for evaluating natural resources. The aim of this study is to monitor changes in forests of Golestan province in two period times from 1990 to 2019, using Landsat images. Accordingly, by incorporating those data sets land use maps are produced. Also, the SVM algorithm is used with six different classes including forest (F), urban area (U), agriculture (A), uncultivated land (UL), water (w) and bare soil (BS). The achieved overall accuracies are $85.48 \%$ and $89.86 \%$. Then the map and matrix changes were obtained by post-classification comparison method. The results showed that the Golestan province's forests were reduced and converted to agricultural and urban land uses.
\end{abstract}

\section{INTRODUCTION}

Ground cover has not been constant over time and is subject to change by human activities (Quintero, et al. 2016). In some cases, this problem can have detrimental effects on human life. In recent decades, due to human activities and various factors such as changing forests to agricultural land and residential areas, cutting down trees to produce wood products, forest fires, soil erosion, construction of roads and power lines, deforestation and deforestation have occurred (Bax, et al. 2016). Therefore, managers 'and experts' awareness of how changes are occurring is an effective factor in managing and planning to prevent deforestation. Remote sensing is one of the useful tools for monitoring changes. Remote sensing images can provide accurate information on the status, extent, and timing of changes (Khoi, Murayama 2011). Recently, various research has been done on deforestation using satellite imagery: (Khoi, Murayama 2011) modeled the changes in the forests of northern Vietnam using neural network and Markov random field, and concluded that forest degradation rates were much higher than in farmland and residential areas. (Schneider, Pontius 2001) applied logistic regression to survey deforestation in Massachusetts, USA, and found that population growth in the area in recent years has led to the expansion of roads and residential areas and the expansion of deforestation in the state. (Sudhakar, et al. 2016) used satellite imagery and the Land Change Modeler method to investigate the extent of deforestation in India between 1930 and 2013, and concluded that about $40 \%$ of India's forests during these years they are removed. The forests of northern Iran are of great value, but in recent years have been transformed into other uses for various reasons. Determining the location and rate of changes occurring in each area can help to manage and monitor this valuable forest. Also, by this investigation, we can control the condition of forests in the past and plan for their restoration. Therefore, the present study aimed to determine forest land-use change in Golestan province using satellite imagery and post-classification method (Hasanlou and Seydi, 2018).

\section{STUDY AREA AND DATASET}

The study area is located in Golestan province in, Iran. Golestan province is located in the neighborhood of Mazandaran, Semnan and North Khorasan provinces. The province has an area of 20367 square kilometres. Two Landsat images that acquired on 30 May 1990 and 30 May 2018 are used for this investigation.

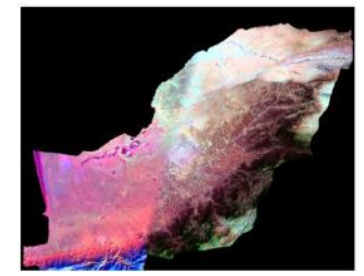

1990

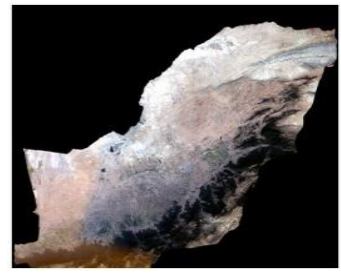

2018
Figure 1. True colour composite of study area for Landsat in 1990 and 2019

The incorporated image data sets specification include Landsat5 and Landsat- 8 satellite imagery, are presented in Table 1 and Table 2.

\footnotetext{
* Corresponding author
} 
Table 1. TM Spectral Bands

\begin{tabular}{ccc}
\hline Band name & Wavelength $(\boldsymbol{\mu m})$ & Resolution $(\mathbf{m})$ \\
\hline 1 & $0.45-0.52$ & $30 \mathrm{~m}$ \\
2 & $0.53-0.61$ & $30 \mathrm{~m}$ \\
3 & $0.63-0.69$ & $30 \mathrm{~m}$ \\
4 & $0.78-0.90$ & $30 \mathrm{~m}$ \\
5 & $1.55-1.75$ & $30 \mathrm{~m}$ \\
6 & $10.4-12.5$ & $120 \mathrm{~m}$ \\
7 & $2.09-2.35$ & $30 \mathrm{~m}$ \\
\hline
\end{tabular}

Table 2. OLI Spectral Bands

\begin{tabular}{ccc}
\hline Band name & $\boldsymbol{\mu m}$ & Resolution(m) \\
\hline 1 & $0.433-0.453$ & 30 \\
2 & $0.450-0.515$ & 30 \\
3 & $0.525-0.600$ & 30 \\
4 & $0.630-0.680$ & 30 \\
5 & $0.845-0.885$ & 30 \\
6 & $1.560-1.660$ & 30 \\
7 & $2.100-2.300$ & 30 \\
8 & $0.500-0.680$ & 15 \\
9 & $1.360-1.390$ & 30 \\
10 & $10.60-11.20$ & 100 \\
11 & $11.50-12.50$ & 100 \\
\hline
\end{tabular}

\section{METHODOLOGY}

The method used in this paper consists of three basic steps: (1) Pre-processing of image data sets, (2) Producing of land use map of each data sets, and (3) Doing change detection. A complete description of each step is introduced as follow.

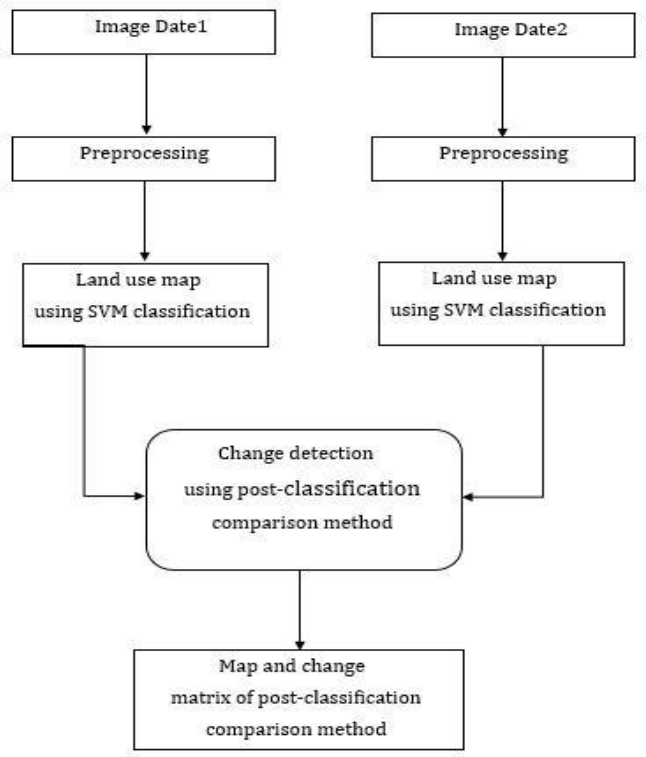

Figure 2. Flowchart of the proposed method

\subsection{Data pre-processing}

At this step, each image was examined for geometrical, atmospheric and radiometric error.

\subsubsection{Atmospheric Correction}

Atmospheric correction is performed to reduce or eliminate the effects of atmospheric diffusion and absorption and to increase the accuracy of land use classification. In this study, atmospheric correction of FLAASH in ENVI5.3 software was used. Atmospheric correction FLAASH is one of the most important atmospheric correction tools for offset and correction of spectral reflections from multispectral reflections and radiations. This correction can accurately compensate for atmospheric effects.

\subsubsection{Geometrical Correction}

In change detection, by comparing each pixel in time 1 with the same pixel at time 2, the changed areas are identified. so the input images must have a good spatial matching so that each pixel in one image corresponds to the same pixel in the other image. So the images need to be geometrically correct and find a suitable location for each other. For this purpose, the 1990 and 2018 images were corrected with maps of 1/25000 scale. Thirty ground control points per image were considered for this task, and the RMSE error for the 1990 image was 0.048 pixels and for the 2018 image was 0.029 pixels.

\subsection{Data Classification}

At this step, the images were classified in six different classes including forest $(\mathrm{F})$, urban area (U), agriculture (A), uncultivated land (UL), water (w) and bare soil (BS).

\subsubsection{SVM}

Support vector machine (SVM) algorithm was used to classify the data. This method is one of the relatively new methods that has shown good performance in recent years compared to older methods for classification (Petropoulos, et al. 2010). The basis of SVM is the linear classification of data. In the linear division of data, we try to select the line that has the most confidence margin. For example, in Figure 3 the line $\mathrm{H}_{2}$ (red) represents the line with the highest margin (optimal line).

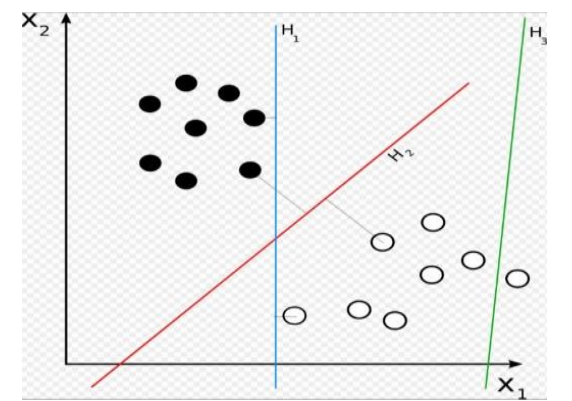

Figure2. View of the line with the highest margins

But if the data are not linearly separated, then we need to move the data to another space using a Kernel Function. Figure 4 shows an overview of data transfer to a higher dimensional space. 


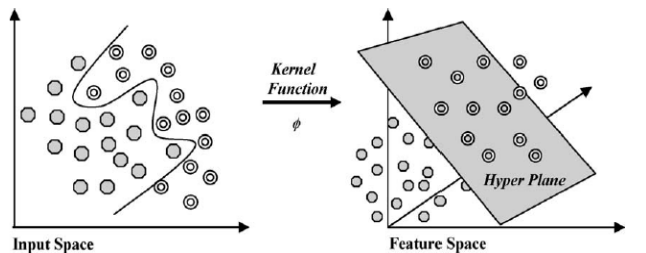

Figure3. An overview of data transfer to another space

SVM has linear, polynomial, RBF and sigmoid kernels (Petropoulos, et al. 2010). In this paper, RBF is used as a kernel function, since it has a higher performance than other kernels, such as sigmoid and linear (Kavzoglu, Colkesen 2009). Table 3 presents the results obtained from tuning parameters for kernel $\mathrm{RBF}$

Table 3. RBF kernel parameters

\begin{tabular}{ccc}
\hline Date & $\mathbf{C}$ & $\gamma$ \\
\hline 1990 & 0.14 & 128 \\
2018 & 0.09 & 64 \\
\hline
\end{tabular}

\subsection{Change Detection}

Change detection is done by post-classification comparison. In this way, it is initially provided separately for each of the maps of the subject map, and then the changes are monitored. One of the most important advantages of this method is to reduce the atmospheric, environmental effects, along with minimizing the effects of using different sensor images, as well as the high accuracy of this method in identifying changes and mapping the nature of the changes (from - To). (Singh, 1989).

The index of change dynamic degree was calculated for each class. This indicator shows the speed of changes per class. The equation (1) represents the change dynamic degree.

$$
K=\frac{u_{b j}-u_{a j}}{u_{a j}} * \frac{1}{T} * 100 \%
$$

where, $K$ indicates the change dynamic degree of type $j$ of land use/land cover during the research period. $U_{b j}$ and $U_{a j}$ refer to the number of pixels of the type $j$ land use / land cover, at the beginning period and ending period respectively, $T$ indicates the intervals (years) between the beginning year and ending year for the research (Jiang, 2011).

\section{RESULTS}

Based on the methodology described above, the results are as follows: Figures 5 illustrate the land use map prepared for the years 1990 and 2018.
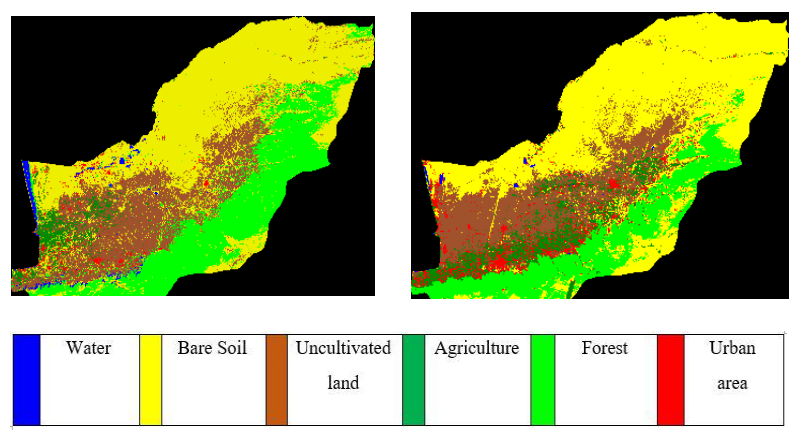

Figure 5. (a). Land use map 1990, and (b). Land use map 2018
The statistical accuracy parameters of classifications images are shown in Table 4

Table 4. Precision Statistical Parameters

\begin{tabular}{ccc}
\hline Date & $\begin{array}{c}\text { Overall } \\
\text { accuracy (\%) }\end{array}$ & Kappa Coefficient \\
\hline 1990 & 85.47 & 0.84 \\
2018 & 89.86 & 0.88 \\
\hline
\end{tabular}

The change map of study is shown in Figure 6

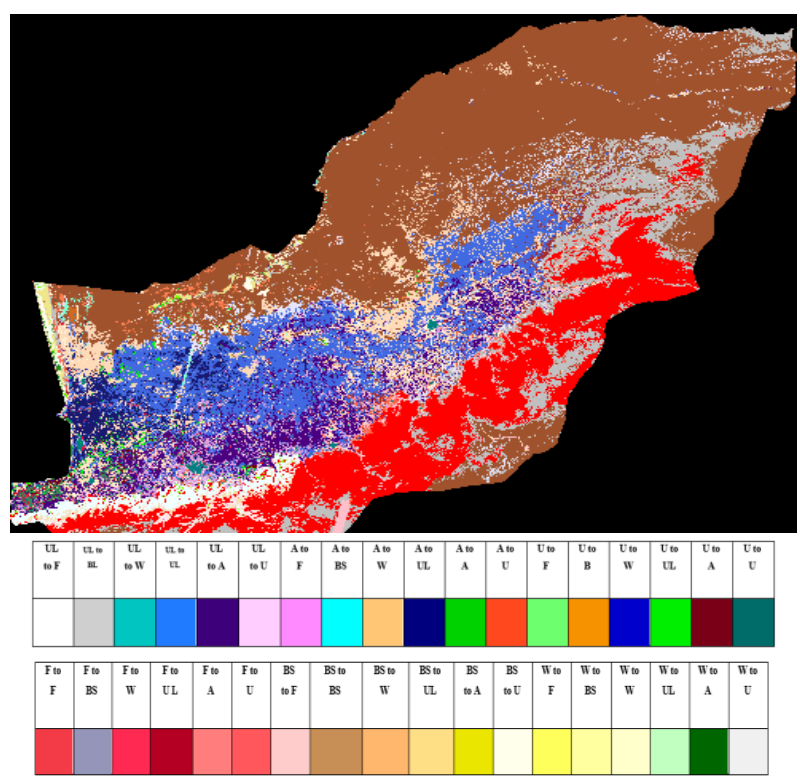

Figure 6. Change map 1990-2018

The changes matrix is shown in Table 5

Table 5. Change Matrix

\begin{tabular}{cccccc|c}
\hline Forest & $\begin{array}{c}\text { Bare } \\
\text { Soil }\end{array}$ & Water & $\begin{array}{c}\text { Uncultivated } \\
\text { land }\end{array}$ & Agriculture & $\begin{array}{c}\text { Urban } \\
\text { area }\end{array}$ & \\
\hline 184614 & 252018 & 36185 & 447543 & 59155 & 88178 & Urban area \\
227870 & 309295 & 17915 & 1036405 & 90038 & 35548 & $\begin{array}{c}\text { Agriculture } \\
\text { Uncultivated } \\
\text { land }\end{array}$ \\
177936 & 1092283 & 9395 & 2404230 & 515813 & 66643 & $\begin{array}{c}\text { Water } \\
2118\end{array}$ \\
1767979 & 8261052 & 81553 & 641358 & 37314 & 83487 & $\begin{array}{c}\text { Bare Soil } \\
3155247\end{array}$ \\
149854 & 78341 & 309513 & 1959 & 14561 & Forest \\
\hline-1806310 & 793184 & -200585 & -577255 & 1012561 & 778388 & Images \\
difference
\end{tabular}


Table 6 shows the dynamics index of each user classes. The degree of the dynamical index indicates the speed of user changes.

Table 6. The change dynamic degree

\begin{tabular}{cc}
\hline Classes & degree of change \\
\hline urban & 9.61 \\
Agriculture & 5.13 \\
Uncultivated land & -0.42 \\
water & -2.86 \\
Bare Soil & 0.28 \\
Forest & -1.17 \\
\hline
\end{tabular}

According to Table 6, urban and agricultural classes had the highest rate of change during the years 1990 to 2018, while the Bare Soil had the least change with a 0.28 percent increase. On the other hand, the forest fell by 1.17 percent, which reflects the decline of forest lands and their conversion into urban, agricultural and Bare Soil.

\section{CONCLUSION}

In this study, forest land-use changes in Golestan province were studied using Landsat satellite images from 1990 to 2018. The results indicate a decrease in the forest area and the development of urban and agricultural areas in the Golestan province. During the years 1990 to 2018, it can be seen that part of the forests has been degraded and become urban areas, agricultural land, and unused land. This can make the environment around human life difficult. so it seems that increasing forest monitoring in the area and informing the public of the damaging effects of deforestation can help reduce the extent of deforestation.

\section{REFERENCES}

Bax, V., Francesconi, W \& Quintero, M (2016). Spatial modeling of deforestation processes in the Central Peruvian Amazon. Journal for Nature Conservation, 29: 79-88.

Jiang, Y., Liu, J., Cui, Q., An, X., \& Wu, C. (2011). Land use/land cover change and driving force analysis in Xishuangbanna Region in 1986-2008. Frontiers of Earth Science, 5(3), 288-293.

Hasanlou, M., Seydi, S.T., 2018. Hyperspectral change detection: an experimental comparative study. International Journal of Remote Sensing 39, 7029-7083. https://doi.org/10.1080/01431161.2018.1466079

Khoi DD, Murayama Y. 2011. Modeling deforestation using a neural Network-Markov model. In: Spatial Analysis and Modeling in Geographical Transformation Process. Springer, pp $169-190$

Kavzoglu T, Colkesen I. 2009, A kernel functions analysis for support vector machines for land cover classification. International Journal of Applied Earth Observation and Geoinformation. 1;11(5):352-9.

Petropoulos GP, Knorr W, Scholze M, Boschetti L, Karantounias G. 2010 Combining ASTER multispectral imagery analysis and support vector machines for rapid and cost-effective post-fire assessment: a case study from the Greek wildland fires of 2007. Natural hazards and earth system sciences. 17;10(2):305-17.

Quintero, G. V., Moreno, R.S., García, M. P., Guerrero, F. V., Alvarez, C.P., \& Alvarez, A. P. (2016). Detection and projection of forest changes by using the Markov Chain Model and cellular automata. Sustainability, 8 (236), 1-13.

Singh, A. (1989). Review article digital change detection techniques using remotely-sensed data. International journal of remote sensing, 10(6), 989-1003.

Schneider, L. C., \& Pontius, R. G. (2001). Modeling land-use change in the Ipswich watershed, Massachusetts, USA. Agriculture, Ecosystems \& Environment, 85(1), 83-94.

Sudhakar Reddy, C., Jha, C. S., Dadhwal, V. K., Hari Krishna, P., Vazeed Pasha, S., Satish, K.V., Dutta. K., Saranya, K. R. L., Rakesh, F., Rajashekar, G \& Diwakar, P. G (2016). Quantification and monitoring of deforestation in India over eight decades (1930-2013), Biodivers Conservation, 25: 93-116 